\title{
RACISMO EN CUBA: CRITTICA A SUS CRÍTICOS
}

\section{RACISM IN CUBA: CRITICISM OF ITS CRITICS}

\section{Noel Manzanares Blanco}

Universidad de Camagüey Ignacio Agramonte Loynaz, Camagüey, Cuba noel.manzanares@reduc.edu.cu

Palabras claves: Racismo; crítica; visiones mutiladas.

Keywords: Racism; criticism; mutilated visions.

Resumen: A modo de Ensayo, se presenta el resultado de una investigaciónacción con el objetivo de contribuir al esclarecimiento de la dinámica de la Revolución Cubana respecto al Racismo a partir de 1959. Particularmente, en seis actos se resalta el contrapunteo con artistas destacados, docentes/investigadores, analistas políticos y activistas contra formas de discriminación social; y queda advertido lo divulgado por el autor desde 2011 en las webs españolas Kaos en la Red y Cubainformación, y su intercambio con colegas y estudiantes. En el contenido sobresale que lo que constituye una aspiración de Naciones Unidas es dinámica perceptible en Cuba, a pesar de que nos queda mucho por hacer -aval para la crítica que ejerzo-. Inicialmente, el esbozo de este título se exhibió en el "VI Encuentro Aponte In Memoriam/2017" efectuado en la ciudad de Camagüey, Cuba.

Abstract: As an essay, the result of an action-research is presented with the aim of contributing to the clarification of the dynamics of the Cuban Revolution with respect to Racism from 1959 onwards. In particular, in six events the counterpoint is highlighted with outstanding artists, teachers/researchers, political analysts and activists against forms of social discrimination; and it is noted what has been disclosed by the author since 2011 in the Spanish websites Kaos en la Red and Cubainformación, and his exchange with colleagues and students. In the content, it stands out that what constitutes an aspiration of the United Nations is perceptible dynamics in Cuba, despite the fact that we still have much to do -endorsement for the criticism that I exercise-. Initially, the outline of this title was exhibited at the "VI Meeting Aponte In Memoriam/2017" held in the city of Camagüey, Cuba. 


\section{Introducción}

En los documentos de la Conferencia Mundial contra el Racismo, la Discriminación Racial, la Xenofobia y las Formas Conexas de Intolerancia efectuada en Durban, Sudáfrica, del 31 de Agosto al 8 de Septiembre de 2001, se lee:

"El racismo, la discriminación racial, la xenofobia y las formas conexas de intolerancia son amenazas y agresiones claras contra la libertad y la dignidad del ser humano, por esta razón, la lucha contra esos males devastadores de la humanidad es una prioridad para la comunidad internacional [...]".

"[Se] Insta a los Estados a que faciliten la participación de los afrodescendientes en todos los aspectos políticos, económicos, sociales y culturales de la sociedad y en el adelanto y el desarrollo económico de sus países, y a que promuevan el conocimiento y el respeto de su patrimonio y su cultura" (ONU, 2001).

Los documentos de la referida Conferencia Mundial, devienen respuesta tangible al compendio de artículos contentivos del repudio al odio racial y el tratamiento del asunto a partir de la percepción de las ciencias como fundamentos de la Organización de las Naciones Unidas para la Educación, la Ciencia y la Cultura (UNESCO, por sus siglas en inglés) para defender la tolerancia y combatir los prejuicios raciales (UNESCO, 1996).

Un observador/a imparcial de la realidad cubana en los últimos 60 años, puede constatar cómo hemos sobrepasado lo que constituye la pretensión de la antirracista Conferencia de la Organización de Naciones Unidas realizada en Sudáfrica a principios de esta centuria. Ilustra al respecto, "Afrodescendencia e inclusión en la Revolución Cubana" con la rúbrica de
Pedro de la Hoz -experto de larga data en el tema (Hoz, 2011)-.

No obstante, otros autores revelan que la problemática racial en Cuba tiene sus retos (Morales, 2010; Feraudy, 2015) y que se ha intensificado el trabajo con sectores juveniles desde los comienzos del siglo actual, aprovechando que estos tienden a rechazarlo -el racismo entre jóvenes lleva la impronta de sus progenitores y del medio social (Torres, 2001)-. Se trata de enarbolar un principio supremo de nuestro Socialismo: la unidad dentro de la diversidad cubana.

En el plano personal, sostengo que la aspiración que tiene la ONU (Organización de Naciones Unidas) en esta trama ha sido cumplida con creces en Cuba, al margen de que tengamos el desafío de concretar mucho, mucho más; y simultáneamente, encuentro pertinente referirme a algunos intelectuales que contradicen la realidad cubana alejados de argumentos científicos, con verdades a medias: apoyados en falsos positivos (supuesta realidad negada en la práctica) y/o fake news (noticias pérfidamente intencionadas). Al respecto, insisto de nuevo en estas líneas.

A modo de Ensayo, es mi objetivo contribuir al esclarecimiento de la dinámica de la Revolución Cubana respecto al Racismo a partir de 1959, en base a estudios sistematizados mediante la investigaciónacción ${ }^{1}$ : en la docencia (con mis colegas y estudiantes de la Universidad de

1. El estudio de una parte importante de la literatura acerca de la investigación-acción en Cuba y otras naciones, me permite acreditar que es un tipo de pesquisa orientada a identificar contradicciones en un objeto de estudio con vistas a trabajar para su solución en la práctica-todo, recurrentemente-. En el campo de la Educación, tiene un amplio escenario; pero también es susceptible su utilización en otras ramas de las Cien- 
Camagüey -lance devenido intercambio/ enriquecimiento-) y en la divulgación/confrontación desde 2011 en Kaos en la Red y Cubainformación, webs alternativas de España. Acerca de ello, inicialmente presenté un esbozo ${ }^{2}$ en el "VI Encuentro Aponte In Memoriam/2017" efectuado en la ciudad de Camagüey, Cuba (León, 2017)³.

Debo aclarar que he optado por privilegiar la bibliografía en soporte digital, porque es más asequible al lector/a en cualquier latitud; por ejemplo, la relacionada con José Martí, Fidel Castro y la Constitución de la República de Cuba. Igualmente, que la pesquisa que realicé para el título que presento me permite asegurar que no abunda la literatura al respecto -menos, en soporte papel-.

cias Sociales. He aquí el porqué la empleo. No es mi propósito, disertar sobre ello.

2. Tres párrafos de lo que escribí en el Epílogo de ese esbozo, los compartí a modo de comentario en "Cuba y los complejos colores del racismo" firmado por Ricardo Ronquillo Bello a finales de 2019. Disponible en: http://www.juventudrebelde.cu/cuba/2019-12-23/cuba-y-los-complejoscolores-del-racismo

3. También contribuyó a nutrir mi ángulo de mira en este orden de ideas, mi participación en la Tercera Escuela Internacional de Postgrado "Paradigmas críticos de la emancipación en el Caribe América Latina" organizada por el Consejo Latinoamericano de Ciencias Sociales (CLACSO) en La Habana en Octubre de 2019. En la ocasión, intercambié acerca del enfoque de género y la discriminación en diversas dimensiones, incluida la racial. Puntualmente, con el debate realizado en la oportunidad aprecié que expertos/as de la región consideran que todavía está por materializarse en la mayoría de países de Nuestra América (Brasil, Colombia...) el llamado de la citada Conferencia en Durban, al tiempo que testimoniaron cómo es peor la situación que viven las mujeres negras, mestizas y originarias del Sur del Río Bravo; contrariamente a lo fundamental que constataron en Cuba sobre el asunto.
Lo que expongo a continuación, tiene un valor agregado: el esclarecimiento de la dinámica de la Revolución Cubana, en el tema que se presenta, constituye un contenido que de diversas maneras se introduce en la "Maestría en Educación Ciudadana" que se concreta en la Universidad aludida en el marco del "Proyecto de Investigación Desafíos de la Educación Ciudadana en la construcción de un socialismo próspero y sostenible" que se desarrolla en nuestra Casa de Altos Estudios como respuesta a prioridades del Ministerio de Educación Superior de Cuba. En tal entramado, este trabajo se convierte en una aportación complementaria 4 .

\section{Primera parte}

\subsection{En torno a conceptos claves}

Para tratar de garantizar el canal de comunicación, preciso aquellos conceptos cuya definición me permite desenredar mi mensaje fundamental.

Entiendo por Racismo -tanto por lo que he investigado 5 como por lo que he vivido

4. La Maestría y el Proyecto en cuestión son conducidos por el Dr. Antonio Sáez Palmero. En mi condición de integrante del claustro docente de esa modalidad de postgrado, conozco que en su programa consta el antirracismo al abordar las temáticas de Las Políticas Públicas y el Enfoque de Género en la Educación Ciudadana en Cuba; y como miembro de la investigación de marras, sé que en su diseño se encuentra lo concerniente a la educación contra el racismo en aras del Socialismo cubano. Por ello, certifico la pertinencia de introducir el Ensayo en causa en la Maestría y Proyecto mencionados.

5. Para el examen de este asunto, pienso que es significativo consultar los Documentos de la Conferencia de Durban/2001 disponible en: http:/www. un.org/es/events/pastevents/cmcr/durban_sp.pdf, 
y/u observado- a la actitud de discriminación por menos precio a una persona atendiendo a su color de piel, rasgos individuales y procedencia social; todo, como estereotipo transmitido de generación en generación amparado en una supuesta naturaleza de inferioridad del individuo despreciado cuya base histórica se encuentra en el surgimiento del proceso de avasallamiento/dominación de unos sujetos (quienes devinieron discriminadores) a otros (quienes se convirtieron en discriminados). Es un atentado contra los derechos de individuos de fisonomía disímiles respecto a las personas ¿desiguales?/dominantes en los ámbitos material y espiritual; al tiempo que tiene lugar en las relaciones interpersonales, en los vínculos grupales y a escala de toda la sociedad.

Para distinguir este fenómeno en el caso de Cuba -y no solamente-, es de gran utilidad el magisterio de José Martí. Si no, medítese en la expresión que continúa:

"Esa de racista está siendo una palabra confusa, y hay que ponerla en claro. El hombre no tiene ningún derecho especial porque pertenezca a una raza u otra: dígase hombre, y ya se dicen todos los derechos. El negro, por negro, no es inferior ni superior a ningún otro hombre: peca por redundante el blanco que dice: 'mi raza'; peca por redundante el negro que dice: 'mi raza'. Todo lo que divide a los hombres, todo lo que lo especifica, aparta o acorrala, es un pecado contra la humanidad [...]" (Martí, 1893).

http://www.un.org/es/events/pastevents/cmcr/ aconf189_12.pdf y http://www.oas.org/es/sla/ddi/ docs/afrodescendientes_instrumentos_internacionales_declaracion_programa_accion_durban.pdf. Vale consultar además, "Significado de Racismo" donde aparece una definición sucinta y otros conceptos relacionados (https://www.significados. com/racismo/) y "Racismo" (https://www.ecured. $\mathrm{cu} / \mathrm{racismo})$.
Es asimismo de utilidad suprema en el asunto del Racismo con epicentro en la nación cubana la percepción de Fidel Castro concretada en las palabras siguientes, cuando apenas había comenzado la Revolución triunfante en el año 1959:

"Quizás el más difícil de todos los problemas que tenemos delante, quizás la más difícil de todas las injusticias de las que han existido en nuestro medio ambiente, sea el problema que implica para nosotros el poner fin a esa injusticia que es la discriminación racial, aunque parezca increíble"./ "[...] hay gente que va a la iglesia y es racista, hay gente que se llama revolucionaria y es racista, hay gente que se llama buena y es racista, hay gente que se llama culta y es racista"./ "Hay gente muy humilde que también discrimina, hay obreros que también padecen de los mismos prejuicios de que pueda padecer cualquier señorito adinerado. $Y$ eso es lo que resulta todavía más triste" (Castro, 1959).

En línea con lo anterior, el Líder Histórico de la Revolución Cubana expuso en la mencionada Conferencia sobre el Racismo en Durban:

"El racismo, la discriminación racial y la xenofobia constituyen un fenómeno social, cultural y político, no un instinto natural de los seres humanos; son hijos directos de las guerras, las conquistas militares, la esclavización y la explotación individual o colectiva de los más débiles por los más poderosos a lo largo de la historia de las sociedades humanas" (Castro, 2001).

En tanto, para dejar constancia de mi presupuesto sobre el núcleo duro de la reflexión que comparto, vuelvo a José Martí:

“[...] Criticar no es morder, ni tenacear, ni clavar en la áspera picota; no es consagrarse impíamente a escudriñar con miradas avaras en la obra bella los lunares y manchas que la afean; es señalar con noble in- 
tento el lunar negro, y desvanecer con mano piadosa la sombra que oscurece la obra beIla. -Criticar es amar [en la perspectiva del progreso humano]" (Martí, S/D).

Es en tal entramado que asumo por Visiones mutiladas a las percepciones que en el tema de marras muestran intelectuales que se convierten en casos representativos por tratar el asunto con verdades a medias: apoyados en falsos positivos (supuesta realidad negada en la práctica) y/o fake news (noticias pérfidamente intencionadas). Son discernimientos de ¿entendidos? en la materia que, de facto, complementan la obra de EEUU contra la Revolución Cubana -un indicador que añade complejidad en cuanto al Racismo en la Mayor de las Antillas-.

No obstante, toda vez que asumo los sucesos y procesos en sus matices detectables, considero que hacer uso de la Crítica en este orden de pensamiento igualmente presupone encontrar el sentido positivo de lo que es objeto de análisis; precisar tanto como humanamente sea posible dónde radica lo que se percibe como errado, desatinado, insuficiente; y además, hacer propuestas tendientes a encontrar solución al problema que se examina ${ }^{6}$. Ello justifica el siguiente acápite.

\subsection{Certezas en visiones mutiladas}

Insisto en que sería desacierto mayúsculo creer que las apreciaciones que distorsionan el pulso de esta temática en la Isla

6. He utilizado este concepto, en varios artículos. A modo de ejemplo, puede verse: Cuba: Criticar, un derecho/deber ciudadano. En: http:// cubainformacion.tv/index.php/la-columna/249noel-manzanares-blanco/72406-cuba-criticarun-derechodeber-ciudadano. Publicado el 13 de Diciembre de 2016. son erradas al cien por ciento. Si a ello se le aplica un examen desprejuiciado, se halla que existen razones puntuales en miradas desfiguradas del asunto. Tal es el caso del historiador africanista Omer Freixa cuando afirma -tras apoyarse en una fuente interna sesgada-: "Es difícil luchar contra doscientos años de vigencia de un modelo, pero no es imposible. No solo es una realidad de Cuba, lamentablemente se repite en otros países americanos con abundante población afrodescendiente" (Freixa, 2014).

¿Dónde radica el problema en la observación de Freixa? Pues en que -al margen de ajustarse a una fuente que no le permite discernir entre lo que ha avanzado la Revolución Cubana y lo que está pendiente- deja en suspenso la diferencia en este aspecto entre la obra de la Isla y "otros países americanos con abundante población afrodescendiente".

Agrego, de paso, que tampoco es del todo un divorcio de la realidad el comentario que sigue colocado en el referido trabajo de Freixa, a saber: "Bueno, yo soy cubana y tengo ya 40 años. No hay realmente racismo en Cuba pero los prejuicios raciales son muchos, se mantiene el tema oculto y se evita hablar de él. El gobierno nunca ha tratado el tema abiertamente pero está ahí, entre ellos mismos".

En correspondencia, certifico que si bien es incierto que "se mantiene el tema oculto y se evita hablar de él" -en el "Sexto acto" del punto siguiente, se aclara-, no deja de tener certidumbre que escasean personas de piel oscura en el conjunto de directivos del sistema político cubano? ${ }^{7}$.

7. Abordé el tema de nuestro sistema político en una serie de cinco trabajos, por la necesidad de polemizar al respecto. En uno, me pronuncié "porque ninguno de los derechos ciudadanos benefi- 
Sin duda, estas son muestras de posiciones que en alguna medida portan tinos sobre la realidad del Racismo en Cuba, aunque al propio tiempo sean susceptibles de ser enriquecidas con miradas de versados nacionales e internacionales que no se quedan en el plano contemplativo.

A modo de ejemplo, resalto -además del citado juicio de Pedro de la Hoz, Vicepresidente de la Unión Nacional de Escritores y Artistas de Cuba (UNEAC)-, el quehacer de la Fundación Nicolás Guillén y la Comisión Permanente de la UNEAC José Antonio Aponte en la conmemoración del Decenio Internacional de los Afrodescendientes proclamado por la ONU para el 2017, como muestra de una labor transformadora en favor de la unidad del "color cubano" (Sautié, 2017); sin dejar atrás a la Tercera Escuela Internacional de Posgrado en La Habana "Más allá del decenio internacional de los pueblos afrodescendientes" que sesionó en Octubre de 2019 (CLACSO, 2019).

\section{Segunda parte}

\section{3.l Contrapunteo con la visión cuestionadora}

Entretanto, sin embargo, asistimos a interpretaciones sobre el Racismo que tienden a negar y/o situar en desconfianza el calado de la Revolución. En este caso, se encuentran desde artistas de renombre y docentes/investigadores hasta analistas políticos y activistas contra formas

cie a unos [individuos] en detrimento de otros". Ver: "Cuba: el pulso de su Sistema Político (2)". Disponible en: http://www.cubainformacion.tv/ index.php/la-columna/249-noel-manzanaresblanco/81680-cuba-el-pulso-de-su-sistema-politico-2. Publicado el 16 de Mayo de 2019. de discriminación social. En contra de la posición de ellos/as, me he pronunciado en reiteradas ocasiones. En conexión con esto, significo sucesos testimoniales en seis actos diferentes.

\subsection{Primer acto}

Redacté "Cosas alrededor de Pablo Milanés" con una inscripción en la que anoté un segmento de una de las canciones más eminentes sobre Cuba de este aclamado canta-autor: "No vivo en una sociedad perfecta/ yo pido que no se le dé ese nombre/, si alguna cosa me hace sentir esta/ es porque la hacen mujeres y hombres". Ello, a propósito de que él refirió en Madrid la "falta de libertades" en nuestro país, según el suplemento Crónica del diario El Mundo, España, en su edición del 14 de Julio de 2008. En esa oportunidad, terminé subrayando: "Mas, a fuerza de ser sincero tengo que exclamar: ¡Pablo, por favor, No te traiciones!" ${ }^{8}$-tal vez sospechando qué podía venir después-.

Luego, aparecieron declaraciones de esta personalidad de nuestra Cultura en el Nuevo Herald -vocero de la extrema derecha cubana desde Miami-:

"[En el juicio de Pablo], uno de los errores de los que controlan actualmente el poder en Cuba es la discriminación contra los negros, que no funciona por decreto, pero sí en la práctica cotidiana. 'Los propios funcionarios del Estado ejercen una discriminación

8. "Cosas alrededor de Pablo Milanés" lo escribí para Kaos en la Red en Julio de 2008, pero hoy no aparece en las páginas de ese sitio. Por esta razón -se repite en otras ocasiones-, el pasaje que aludo lo cito desde "Pablo Milanés: ¿Una actitud obligatoria en Madrid y Miami? que también escribí para Kaos y ahora solo aparece su reproducción en el Fanal Cubano. 
que proviene de 400 años de dominación blanca sobre los negros. Mentalmente no han podido superar esto y por eso se crean castas y relevos de puestos dentro de las familias y privilegios que no tienen los negros', dijo Milanés [...]" (El Nuevo Herald, 2011).

Ante esas palabras, escribí "Pablo Milanés: ¿Una actitud obligatoria en Madrid y Miami?" (Manzanares, 2011) para hacer constar que por razones obvias [soy de tez oscura] daba fe de que a partir de 1959 la obra de nuestra Revolución estaba/está a favor de las personas de piel negra, incluyendo la Educación cada vez más distanciada de la discriminación; y que, no obstante, en este asunto sí quedaban/quedan rezagos que pensaba/pienso están muy bien explicado en el rótulo "Gerardo Alfonso: 'Para mí el racismo es un tema eminentemente cultural'" (Pérez, 2010).

Ahora, con el ánimo de indicar cómo aparecen verdades a medias (falsos positivos -supuesta realidad negada en la práctica- y/o fake news -noticias pérfidamente intencionadas-), llamo su atención: la coincidencia Milanés-Herald conlleva a presentar el racismo en Cuba como acto consustancial a su Revolución, como un problema que, lejos de resolverse, se aúpa -lance que la práctica en la Isla refuta-.

\subsubsection{Sequndo acto}

Después, apareció "Para los negros en Cuba la Revolución no ha comenzado aún" de Roberto Zurbano (Zurbano, 2013). El título, se convirtió en motivo de varios trabajos a favor y en contra; y en lo personal, tras leer su contenido, quedé con una apreciación relativamente negativa porque no compartí ni comparto la integralidad de ese texto, independientemente de que sí estaba/estoy de acuerdo con su espíritu y encontré positivo que el autor acusara a The New York Times (NYT -donde se publicó originalmente el título-) "de manipulaciones y violaciones éticas" en una entrevista posterior con Associated Press (AP, 2013).

Debo insistir en que cuando Zurbano se quejó ante AP del título "Para los negros...", manifestó que su propuesta era más bien que la Revolución "no ha terminado" para los/as descendientes de África, y le confesó a esa Agencia de EEUU: "Sigo pensando las mismas ideas, sobre el racismo hay mucho que discutir todavía". "Esa es mi lucha y va a seguir siendo mi lucha dentro y fuera de Casa de las Américas, pero siempre dentro de la Revolución".

Sin embargo, un analista político integrante de la ¿nueva? "izquierda" radicada en el territorio nacional, Pedro Campos, se sintió en el deber de difundir "Zurbano se quedó corto" y la siguiente inscripción: "La revolución socialista no ha llegado para los negros ni para los blancos, para ningún cubano: sigue pendiente" (Campo, 2013).

Frente a este episodio, firmé "Roberto Zurbano, Pedro Campos y el Negro/a en Cuba" donde una vez más acredité lo mucho que ha realizado la Revolución Cubana a favor de la igualdad racial, sin desconocer limitaciones indicadoras de cuánto queda por hacer; a la vez que destaqué que el propio Campos en un momento determinado arremetió contra el proceso que lidera el Partido Comunista de Cuba en once de un total de 13 trabajos (más de las 4/5 partes -solo en el ejemplo que cito-), y hasta llegó a poner en tela de juicio el servicio de Yoani Sánchez a favor de la CIA (Manzanares, 2013).

Mientras, me pregunté cómo fue posible que un intelectual como Zurbano cayera en una ¿trampa? del NYT, si es un secre- 
to a voces que prácticamente no existe voluntad en la denominada prensa occidental de contar con trabajos de autores cubanos o de otras nacionalidades que aborden con la mayor objetividad posible el tema del Racismo en la Isla o cualquier temática compleja. Fue lamentable, pues, que Roberto apareciera vinculado con verdades a medias (falsos positivos -supuesta realidad negada en la práctica-y/o las fake news -noticias pérfidamente intencionadas-).

\subsubsection{Tercer acto}

En 2016 se publicaron varios rótulos que me convocaron a continuar mi labor de esclarecimiento sobre el tema del Racismo en Cuba, incluyendo dos relacionados entre sí que, sin embargo, no clasifican exactamente como contrarios a nuestra Revolución.

En el Periódico Tribuna de La Habana apareció "Negro ¿tú eres sueco?", a propósito de la visita que realizó a La Habana el entonces Presidente Barack Obama (Agudín, 2016), y me situé entre las personas que apreciamos un viso de racismo en ese título, al margen de que me atreví/ atrevo a asegurar que no fue objetivo del autor lastimar al entonces principal inquilino de la Casa Blanca ni dañar la imagen del negro en Cuba. Pero ello provocó un artículo que en mi opinión no debía pasar inadvertido.

El especialista en relaciones Cuba-EE. UU. y editor del Blog El Heraldo Cubano, Arthur González, difundió "¿Por qué decir negro es racismo?" (González, 2016) ante las reacciones por el título referido al exmandatario Obama. Se trata de un razonamiento que encontré adecuado en el marco de la subversión ideológica del
Águila Imperial vs. el Caimán Verde, pues el asunto del Racismo constituye una variable para atacar a nuestro proceso revolucionario y dividirnos en un polo de blancos/as y contrincantes negros/as.

No obstante, entendí/entiendo que la tesis de Arthur "Para algunas personas de la raza negra, mencionarlos por ella es algo ofensivo e insultante, tomándolo, sin razones objetivas, como una muestra de discriminación racial", merecía ser complementada por cuanto, en su defecto, podía provocar un resultado contrario al deseado.

En aquel momento, tuve a bien ilustrar el tema con tres ejemplos relacionados con mi propia experiencia. Los reitero:

“En primer lugar, recuerdo perfectamente que en mi Camagüey llamaban 'Reparto Prieto' a un área ubicada próxima de mi casa durante mi niñez y adolescencia en la que vivían mayoritariamente negros/as que exhibían un número significativo propenso a delinquir. Así, pregunto: ¿Será que por casualidad le otorgaron esa denominación a ese espacio camagüeyano o más bien se hizo en alusión al supuesto carácter negativo de la representación étnica en causa?

“También en mi memoria guardo la ocasión en la que, durante una sesión de la Asamblea Municipal del Poder Popular de mi terruño a finales del siglo pasado, mientras se debatían las propuestas para postulados/ as a la Asamblea Nacional, un Delegado se cuestionó el hecho de que en la candidatura apenas estaban negros/as e inquirió mirando hacia mi persona: '¿Acaso a nosotros no nos gusta ser Diputado?'. En ese minuto, precisamente por mi ascendencia relativa en los reunidos porque como Profesor impartía Conferencias de temas de actualidad política a mis colegas Delegados/as de esa instancia intermedia, opté por aceptar la respuesta dada que no me convenció mu- 
cho -so pena de estimular una segmentación que potencialmente dañaría a nuestra Revolución-.

"Además, retengo en mi mente una anécdota con la Madre de una compañera de trabajo. Resulta que de vez en vez tenía que llamar a su casa para consultar y/o ponernos de acuerdo en algún lance laboral, y en la oportunidad intercambiaba unas palabras con la Progenitora que siempre atendía el teléfono. Mas, cuán grande fue mi sorpresa el día en que tuve que personarme en el hogar y dialogar con la Mamá: ella preguntó qué deseaba y quién era; yo me identifique. Entonces, exclamó: ‘Ah, yo pensé que usted era blanco!'. Huelgan comentarios" (Manzanares, 2016a).

Apenas agrego que los ejemplos anteriores están enmarcados en "razones objetivas" asumidas como manifestación de un reflejo condicionado que no siempre obedece a la voluntad de la persona que discrimina sino que se encuadran en un rezago cultural trasmitido de una generación a otra.

\subsubsection{Cuarto acto}

Otro juicio se deriva de la entrevista a la antropóloga, periodista y profesora cubana María Ileana Faguaga realizada por el órgano de prensa Brasil de Fato publicado con el rótulo "Ser negra en Cuba" (Gonçalves, 2016). Con sus apreciaciones, floreció la verdad a medias.

Una vez en conocimiento del contenido de la entrevista concedida por la también activista de derechos humanos e historiadora, sentí motivación para escribir "Cuba: aristas de personas de piel oscura" (Manzanares, 2016b) donde sostuve que ella adelanta con acierto: "No podemos ser verdaderamente revolucionarios si somos racistas. Si todavía utilizamos métodos de colonización"; al paso que acredita que el nivel de conciencia racial de las mujeres aumentó y "articulan muy bien su pensamiento y tiene una capacidad de lucha fuerte contra el patriarcado del hombre afrocubano".

Expresé, no obstante, que María lleana Faguaga responde en términos absolutos a la pregunta "¿Qué significa ser una mujer negra cubana?", al decir: "Significa ser invisibilizada, como ocurre con las mujeres negras de las Américas y probablemente de todo el mundo", y luego agregar: “[...] Hay, por ejemplo, una tentativa de ocultar que la mayoría de la población cubana es negra. Según el Censo [¿de 2012?'?"

En rigor, encontré más tino en el razonamiento de la académica Daysi Rubiera que parte del reconocimiento de que el activismo contra el racismo en Cuba se consolida y replantea estrategias de trabajo ante el florecimiento de desigualdades por género y color de la piel tras las transformaciones sociales de lo que llamamos Actualización del modelo cubano (IPS, 2015).

Esta percepción de Rubiera, también historiadora, coincide con el examen de la Dra. en Ciencias Psicológicas María del Carmen Zabala Argüelles en "Equidad social y cambios económicos en Cuba: retos para la atención a la pobreza y desigualdades" (Espina y Echevarría, 2015). Tal realidad, sin embargo, no implica un reconocimiento a la expresión de que la

9. Los datos que maneja esta autora, contradicen el Informe Nacional - Resultados definitivos de indicadores seleccionados en Cuba, Provincias y Municipios. Oficina Nacional de Estadística e Información (2012). Censo de Población y Viviendas. Disponible en: http://www.one.cu/informenacional2012.htm. 
mujer de piel oscura en la Isla está "invisibilizada, como ocurre con las mujeres negras de las Américas y probablemente de todo el mundo".

Por demás, en "Cuba: aristas..." traje a capítulo asimismo que Beatriz Marcheco Teruel, especialista en Genética clínica del Centro Nacional de Genética Médica de La Habana, había compartido datos interesantes a los efectos del asunto en cuestión: precisó características genéticas de los cubanos/as de acuerdo con la tez que ostentan, y evidenció cómo un por ciento considerable de personas de piel clara poseen genes africanos; cómo personas de piel oscura revelan un número significativo de genes europeos; y cómo en las personas mestizas "La proporción de genes de origen europeo en estos individuos varía desde 19,6\% hasta 96,9\% y la de origen africano desde 2,4\% hasta 70,2\%" (Marcheco, 2013).

Empero, lo expuesto no desacredita a otro estudio científico que revela:

"Hay consenso en que el tema no es tratado como debería serlo dada la proliferación de manifestaciones racistas". "La mayoría (89\%) considera que se requiere de una legislación y una institución específicas para tratar las manifestaciones racistas, puesto que dan una garantía jurídica y constituyen un acto de justicia social'" (Cuba, 2019) aspecto ya articulado, como se ejemplifica más adelante-.

Acredito, pues -y en contraposición al punto de vista de María lleana Faguaga-, que ante el Racismo en Cuba es indispensable una reflexión desprejuiciada y científica contra las miradas absolutas devenidas verdades a medias (falsos positivos -supuesta realidad negada en la práctica-y/o fake news -noticias pérfidamente intencionadas-).

\subsubsection{Quinto acto}

En este punto, abordo la confrontación que sostuve a partir de la percepción de "Negra cubana tenía que ser" y su relato del "delito" de ser negro en la Mayor de las Antillas. Ella manifestó:

"I- Quizás pueda Alex inscribir en los Récord Guinness una marca: la policía cubana ha llegado a pararlo en la calle 5 veces en un mes. De manera que ha pasado repetidamente largas jornadas en estaciones habaneras de policía. Ya conoce todo el procedimiento, paso a paso, lo que va a suceder. Solo el humor que Alex le pone a la vida le ha permitido contar sus 'historias policiales'. Su único delito es ser negro".

"V- En unas de sus visitas a La Habana, Armando me confesó que su angustia se dispara cuando visita 'la capital de todos los cubanos', ante la posibilidad de que le pidan el carnet y le maltraten [...]. Su único delito: ser negro (y oriental)".

"Epílogo: Habrá quien me diga que en Estados Unidos les matan. Es cierto. Pero en la Isla del color cubano, que la policía pare a los jóvenes negros atendiendo a perfiles raciales, es una copia genuina de sociedades donde efectivamente te matan por tu color de piel o tu nacionalidad. En la Isla dicho asunto transcurre, hasta el momento, entre maltratos, amenazas, extorsiones, arrestos indebidos, abusos, golpes... ¿Les parece poco?" (Álvarez, 2016).

En este cuento, aprecié un marcado divorcio con "recomendaciones ético-sintácticas" (Buen Abad, 2016) y, consiguientemente, concebí "Cuba: ¿los Negros/as son objetos de discriminación?" (Manzanares, 2016c) para dejar constancia de qué me había provocado la lectura del trabajo sobre el "delito" de tener la piel oscura en nuestra Revolución; mientras que resalté argumentos como los abordados en 
el "Cuarto acto" de este Ensayo y reiteré lo que considero sintetiza el desatinado ¿razonamiento? de "Negra cubana" -en la evaluación de alguien que evidencia su imparcialidad-:

"Muy atinado, muy equilibrado el texto de Noel, a quien en otras ocasiones he criticado. Excelente. No me parece tan correcta la actitud -más que posición- de la Negra cubana [tenía que ser -del referido Blog-], que desde hace ya años escribe únicamente para dar palo, sin equilibrio, con demasiada visceralidad. Esto -menos en una guerra que no ha acabado, sino que se ha modificado para confundir- no sirve para la deconstrucción de los errores (el no socialismo dentro del socialismo), sino para crispar y polarizar a las personas que se definen como revolucionarias y obstaculiza la necesaria limpieza de la maleza burocrática, ramplona y oportunista. Que me disculpe la Negra cubana, a quien no niego su buena intención y su posición revolucionaria, que conste.../ Ramón Neruda, lunes, 01 de agosto de 2016".

Considero, pues, que para "Negra cubana" la verdad ni siquiera es a medias: en ella emergen multiplicado por el infinito los falsos positivos (supuesta realidad negada en la práctica) y/o fake news (noticias pérfidamente intencionadas). No obstante, reconozco que en torno al Racismo en Cuba puntualmente aparecen episodios vergonzosos. Ejemplifico:

Soy parte de los cubanos/as que reaccionamos con indignación cuando conocimos que Yanay Aguirre Calderín, a la sazón estudiante de sexto año de la carrera de Derecho en la Universidad de La Habana, fue víctima de un chofer (¿trabajador? por cuenta propia), quien le vociferó ante una rectificación de la joven: "cada vez que se montaba un negro en su carro era lo mismo y que por eso no los soportaba".
Al hacerme eco de este penoso suceso, al tiempo que pregunté si era preciso reactivar más el pensamiento de José Antonio Aponte ${ }^{10}$, sostuve que este hecho de discriminación racial tangible convoca a pensar cuánto más se puede/debe hacer para tributar a desarraigar esa lacra humana -tal como hacen otros promotores vs. diversas diferenciaciones aberrantes (Manzanares, 2017)-. Hoy, se refuerza este combate -como trato a renglón seguido-.

\subsubsection{Sexto acto}

Justo con los finales de la segunda década del presente siglo, acontecimientos trascendentales se convirtieron en indicadores de que estaba comenzando una nueva etapa para el abordaje del asunto principal de este trabajo y de otros temas de suma importancia para la sociedad cubana. Me refiero, ante todo, a la Carta Magna aprobada por la inmensa mayoría de nuestro pueblo y proclamada el 10 de Abril de 2019.

10. Aponte (1760-1812) fue un negro libre nacido en la Isla y llegó a dominar varios oficios: carpintero, tallador y ebanista. Alcanza celebridad al dirigir la primera sublevación de carácter nacional contra la esclavitud y a favor de nuestra independencia que registra la Historia de Cuba; esfuerzo que pagó con su vida. Lo considero protomártir del movimiento emancipatorio cubano. Tan revolucionario fue en su época, que para desprestigiarlo los colonialistas y racistas auparon la expresión: "Más malo que Aponte". Al respecto, puede consultarse: "Bicentenario del movimiento revolucionario liderado por José Antonio Aponte Ulabarra" escrito por Felipe de J. Pérez en 2012, disponible en: http://www.lajiribilla.co.cu/2012/n571_04/571_21.html y “En el principio fue Aponte" con la rúbrica de Pedro de la Hoz en 2019, disponible en: http://www. granma.cu/cuba/2019-04-08/en-el-principio-fueaponte-08-04-2019-21-04-06. 
No es un dato secundario que en el articulado de nuestra Constitución conste:

"Artículo 1. Cuba es un Estado socialista de derecho y justicia social, democrático, independiente y soberano, organizado con todos y para el bien de todos [...]".

"Artículo 42. Todas las personas son iguales ante la ley [...] sin ninguna discriminación por razones de sexo, género, orientación sexual, identidad de género, edad, origen étnico, color de la piel, creencia religiosa, discapacidad, origen nacional o territorial, o cualquier otra condición o circunstancia personal que implique distinción lesiva a la dignidad humana" (Asamblea Nacional del Poder Popular, 2019).

Resultó coherente, pues, que entre los trabajos contra el Racismo en Cuba que emergieron con la nueva luz constitucional esté el que aconseja: "[...] Recordemos un concepto meridiano expuesto por ese notable intelectual revolucionario que fue Fernando Martínez Heredia: 'La lucha por la profundización del socialismo en Cuba está obligada a ser antirracista"" (Hoz, 2019).

No obstante, a los efectos de este Ensayo lo que considero muy significativo es un documento aprobado por el Gobierno de Cuba casi al finalizar el 2019, a saber:

En una reunión del Consejo de Ministros de la Mayor de las Antillas

"fue dado a conocer el Programa Nacional contra el racismo y la discriminación racial, que se ha concebido 'para combatir y eliminar definitivamente los vestigios de racismo, prejuicios raciales y discriminación racial que subsisten en Cuba'". "El Programa Nacional que ahora se crea incluirá la lucha contra el regionalismo y la discriminación por el origen étnico y nacional, manifestaciones asociadas también al racismo". "Para coordinar las tareas se creará una
Comisión Gubernamental, encabezada por el Presidente de la República [Miguel DíazCanel Bermúdez]" (Consejo de Ministros de Cuba, 2019).

Como era de esperar, hubo posiciones de poco entusiasmo de cara al Programa en cuestión, de acuerdo con lo que sigue:

"El escritor y activista cubano Roberto Zurbano saludó la decisión del Gobierno de lanzar un programa nacional 'contra el racismo y la discriminación racial', pero recordó que se trata de "una noticia que no sorprende a muchos de los que hemos estado despiertos y despertando a muchos otros sobre la creciente presencia del racismo en Cuba'". "[Zurbano] advirtió que no es la primera vez que el Gobierno lanza una de estas iniciativas, y que las anteriores terminaron su labor demasiado limitadas, silenciadas y sin efecto, con muchas ideas abortadas'" (DDC, 2019).

De aquí, a modo de juicio breve destaco un detalle: el órgano que se hace eco de la actitud de Zurbano es un medio digital contrario a nuestra Revolución -acredito de ese modo, en uso de la decencia-. Y, una vez que recuerdo estar en presencia de la misma persona que confesó ser víctima "de manipulaciones y violaciones éticas" de The New York Times, pregunto/ convoco a la meditación de mis lectores/ as: ¿Será un suceso casual la coincidencia entre el "escritor y activista cubano" y el medio que le sirvió de vocero?

Pero, como asimismo era de esperar, hubo más repercusiones positivas ante el Programa de marras que vino a reforzar la verdad vs. falsos positivos (supuesta realidad negada en la práctica) y/o fake news (noticias pérfidamente intencionadas).

Víctor Fowler, a la vez que reconoce a este Programa como "una noticia cuando menos trascendente", sentencia sin miramientos: 
"[...] la única forma de no ser racista es no siéndolo; o sea, expresando -de manera activa- el disgusto o la molestia ante cualquier acto o expresión racista, exteriorizándolo, compartiendo con el que padece. Esto quiere decir que, en las condiciones del presente, diferentes a las de aquel universo de complicidad estructural típico de las sociedades coloniales, la indiferencia o el silencio cómplice ante el racismo contribuyen a la infiltración del veneno atmosférico del odio y el desprecio" (Fowler, 2019) -e invito a valorar todo el texto escrito por Fowler-.

Así, en un balance de ideas contrapuestas, auguro que el hecho de contar con un "Programa Nacional contra el racismo y la discriminación racial" va a constituir un auténtico parteaguas en el camino de extirpar el Racismo en Cuba y pasar en este orden de sentipensamiento a una etapa cuantitativa y cualitativamente superior.

Por demás, considero que específicamente la valoración en torno a este Programa -en tanto que reflejo tangible del objetivo declarado del autor- de facto refuerza el valor agregado de este Ensayo para su empleo en la "Maestría en Educación Ciudadana" y el "Proyecto de Investigación Desafíos de la Educación Ciudadana en la construcción de un socialismo próspero y sostenible" aludidos.

\section{Conclusiones}

El estudio del estado actual y perspectivo del Racismo en Cuba debe tener entre sus referencias lo tratado y derivado de la Conferencia Mundial contra el Racismo en Durban.

Mas, para el análisis de este asunto no debe obviarse que lo que constituye una aspiración de Naciones Unidas en esta trama es dinámica perceptible en el caso de Cuba, a pesar de que nos queda mucho por hacer. Ello avala la razón que me acompaña para criticar a nuestros críticos/as acerca del Racismo en medio de nuestra Revolución, con el magisterio de José Martí y Fidel Castro, y de acuerdo con mi pesquisa-actuación al respecto.

No obstante, es absurda la creencia de que los señalamientos que nos hacen en esta temática son errados absolutamente. Pienso que, por lo menos, resultan necesarias reflexiones recurrentes que nos conduzcan cada vez más a dejar atrás cualquier tipo de discriminación, específicamente la relacionada con las personas de piel oscura.

Sin lugar a duda, merece un saludo lo realizado por la Fundación Nicolás Guillén y la Comisión Permanente de la UNEAC José Antonio Aponte ante el Decenio Internacional de los Afrodescendientes, así como la Tercera Escuela Internacional de Posgrado en La Habana que le dio continuidad al asunto; y amerita una ovación, si cada quien, desde su respectivo accionar, brinda su contribución ante el flagelo en causa.

Puntualmente, los diversos sucesos testimoniales que constan en los seis actos aquí tratados -en rigor, representan la necesidad de aborda el particular de esta discriminación frente a verdades a medias enarboladas por intelectuales que se supone no tengan la intención de complementar la Guerra multilateral de EEUU contra Cuba-, no solo indican cuánta complejidad encierra el tema del Racismo en la Mayor de las Antillas sino, igualmente, la pertinencia de defender lo que hemos alcanzado en este orden de ideas y continuar nuestro avance en contra de menosprecio por el color de la piel. 
En otras palabras, el problema de la racialidad abordado ha de conllevarnos a luchar sin descanso contra la supuesta verdad que encierra falsos positivos (supuesta realidad negada en la práctica) y fake news (noticias pérfidamente intencionadas)-expresión que he reiterado adrede-.

En perspectiva, contamos con una fortaleza marcada: el "Programa Nacional contra el racismo y la discriminación racial" que lidera nuestro Presidente Díaz-Canel. El reto, es cómo ir por más y mejor en este asunto o sea, cómo los actores involucrados en el tema -sujetos aptos para influir en la trasformación positiva de la trama en cuestión en todos los ámbitos y jerarquía del quehacer cotidiano- dan su tributo y siguen enriqueciendo al ser humano para extinguir el Racismo y otras maneras de segregación de las personas en Cuba.

Finalmente, certifico que cuanto he expuesto en este Ensayo desde mi investigación-acción deviene valor agregado porque -más allá de revelar cuán importante es encarar el asunto en cuestión desde una óptica objetiva- constituye un sistema de ideas susceptible de utilizarse como literatura complementaria en la Maestría y Proyecto citados que desarrollamos en la Universidad de Camagüey acerca de la Educación Ciudadana en aras de nuestro "socialismo próspero y sostenible".

\section{Bibliografía}

Agudín, E. (2016). Negro, ¿tú eres sueco? [en línea]. Recuperado 27 de Marzo 2016 de, http://www.tribuna.cu/sites/default/files/PDFs/12/PAG\%203-27_opt.pdf.

Álvarez, S. (2016). Cuando ser negro es un delito. [en línea]. Recuperado 15 Septiembre 2016 de, http://www.cubain- formacion.tv/index.php/la-columna/229sandra-alvarez/70804-cuando-ser-negroes-un-delito.

AP. (2013). Roberto Zurbano acusa a NYT de manipulaciones y violaciones éticas. [en línea]. Recuperado 08 Octubre 2016 de, http://www.lajiribilla.cu/articulo/4251/ roberto-zurbanoacus\%c3\%b3alnytdema nipulaciones-y-violaciones-eticas.

Asamblea Nacional del Poder Popular. (2019). Constitución de la República de Cuba. [en línea]. Recuperado 16 Abril 2019 de,http://media.cubadebate.cu/wp-content/ uploads/2019/04/Constituci\%C3\%B3n-dela-Rep\%C3\%BAblica-de-Cuba.pdf.

Buen Abad, F. (2016). Diez recomendaciones ético-sintácticas. [en línea]. Recuperado 27 Julio 2016 de, http://www. cubadebate.cu/opinion/2016/07/27/diezrecomendaciones-etico-sintacticas/\#. V5oQgY-VtMY.

Campos, P. (2013). Zurbano se quedó corto. [en línea]. Recuperado 17 Mayo 2013 de, http://www.kaosenlared.net/ america-latina/item/57123-zurbanosequed\%c3\%b3-corto.html.

Castro, F. (1959). Quizás el más difícil de todos los problemas: la discriminación racial. [en línea]. Recuperado 08 Octubre 2016 de, http://www.granma.cu/granmad/ secciones/fidel_en_1959/art-048.html.

(2001). Discurso en la Sesión Plenaria de la Conferencia Mundial contra el Racismo, la Discriminación Racial, la Xenofobia y las Formas Conexas de Intolerancia, Durban, Sudáfrica. [en línea]. Recuperado 08 Octubre 2016 de, http:// www.cuba.cu/gobierno/discursos/2001/ esp/f010901e.html.

CLACSO. (2019). Más allá del decenio internacional de los pueblos afrodescendientes. [en línea]. Recuperado 07 Abril 2020 de, https:/www.clacso.org/ mas-alla-del-decenio-internacional-delos-pueblos-afrodescendientes/. 
Consejo de Ministros de Cuba. (2019). Programa contra el racismo y la discriminación. [en línea]. Recuperado 30 Noviembre $2019 \mathrm{de}$, http://misiones.minrex. gob.cu/es/articulo/no-vamos-renunciarlas-conquistas-y-los-suenos-por-realizarafirma-presidente-cubano-en.

Cuba, L. (2019). Políticas para la equidad racial. Retos en el contexto cubano actual. [en línea]. Recuperado 07 Abril 2020 de, http://scielo.sld. $\mathrm{cu} / \mathrm{scielo}$.php?script=sci_arttext\&pid $=$ S2308-01322019000200012.

DDC. (2019). Roberto Zurbano recuerda al Gobierno cómo terminaron sus anteriores iniciativas 'antirracistas'. [en línea]. Recuperado 30 Noviembre 2019 de, https://diariodecuba.com/ cuba/1574621001_6455.html.

El Nuevo Herald. (2011). Pablo Milanés critica falta de libertades y discriminación en Cuba. [en línea]. Recuperado 20 Agosto 2011 de, https://www.cibercuba. com/noticias/2011/08/15/pablo-milanes-critica-falta-de-libertades-y-discriminacion-en-cuba.

Espina, M. y Echevarría, D. (2015). En Cuba: los correlatos socioculturales del cambio económico. Ciencias Sociales. Ruth Casa Editorial, p. 41.

Feraudy, H. (2015). ¿Racismo en Cuba? Editorial de Ciencias Sociales, La Habana. Fowler, V. (2019). Pensando en clave de "raza". [en línea]. Recuperado 07 Enero 2020 de, http://www.cubadebate.cu/especiales/2019/12/26/pensando-en-clavede-raza/\#.XgTabvx7kb0.

Freixa, O. (2014). Negritud y racismo en Cuba. [en línea]. Recuperado 08 Octubre 2016 de, http://blogs.elpais.com/africano-es-un-pais/2014/09/el-negro-cubano. html.

Gonçalves, J. (2016). Ser negra en Cuba. [en línea]. Recuperado 31 Julio 2016 de, http://kaosenlared.net/brasil-ser-negraem-cuba/.

González, A. (2016). ¿Por qué decir negro es racismo? [en línea]. Recuperado 04 Abril 2016 de, http://www.cubainformacion.tv/index.php/la-columna/255arthur-gonzalez-heraldo-cubano/68190ipor-que-decir-negro-esnracismo.

Hoz, P. de la (2011). Afrodescendencia e inclusión en la Revolución Cubana. [en línea]. Recuperado 30 Octubre 2016 de, http://www.foroscubarte.cult.cu/read. php?14,247307.

- (2019). El socialismo tiene que ser antirracista. [en línea]. Recuperado 29 Noviembre 2019 de, http:// www.granma.cu/cuba/2019-11-20/ el-socialismo-tiene-que-ser-antirracista-20-11-2019-23-11-07.

IPS. (2015). Cuba requiere actualizar lucha contra nuevas formas de racismo. [en línea]. Recuperado 17 Febrero 2016 de, http://www.ispnoticias.net/2015/02/ cuba-requiere-actualizar-lucha-contranuevas.formas-de-racismo/.

León, Y. (2017). En Camagüey encuentro José Antonio Aponte in memoriam. [en línea]. Recuperado 07 Abril 2020 de, http://www.adelante.cu/index.php/es/ noticias/de-camagueey/8526-ofrendafloral-para-lideres-negros-ahorcados-encamagueey.

Manzanares, N. (2011). Pablo Milanés: ¿Una actitud obligatoria en Madrid y Miami? [en línea]. Recuperado 20 Agosto 2011 de, http://fanalcubano.blogspot. com/2011/08/pablo-milanes-una-actitudobligatoria.html.

(2013). Roberto Zurbano, Pedro Campos y el Negrola en Cuba. [en línea]. Recuperado 17 Mayo 2013 de, http://2014.kaosenlared. net/secciones/s2/biblioteca-digital-qla-cosechaanticapitalistaq/57264-roberto-zurbanopedro-campos-y-el-negro/a-en-cuba. 


\begin{abstract}
- (2016a). Cuba: en ocasiones, decir 'negro' es racismo. [en línea]. Recuperado 05 Abril 2016 de, http:// www.cubainformacion.tv/index.php/ la-columna/249-noel-manzanaresblanco/68201-cuba-en-ocasiones-decirnegro-es-racismo.
\end{abstract}

(2016b). Cuba: aristas de personas de piel oscura. [en línea]. Recuperado 01 Agosto 2016 de, http://cubainformacion.tv/index.php/la-columna/249-noel-manzanares-blanco/70154-cuba-aristas-de-personas-de-piel-oscura.

- Cuba: ¿los Negros/as son objetos de discriminación? [en línea]. Recuperado 17 Septiembre 2016 de, http://cubainformacion.tv/index.php/ la-columna/249-noel-manzanaresblanco/70831-cuba-ilos-negrosas-sonobjetos-de-discriminacion.

(2017). Cuba: ¿Será preciso reactivar más el pensamiento de José Antonio Aponte? [en línea]. Recuperado 11 Julio 2017 de, http://historico.cubainformacion. tv/index.php/la-columna/249-noel-manzanares-blanco/75528-cuba-isera-preciso-reactivar-mas-el-pensamiento-dejose-antonio-aponte.

Marcheco, N. (2013). Estudio muestra que en el $A D N$ del cubano están todas las razas. [en línea]. Recuperado $17 \mathrm{Fe}-$ brero 2016 de, http://www.cubadebate. cu/noticias/2013/10/09/estudio-muestraque-en-el-adn-del-cubano-estan-todaslas-razas/.

Martí, J. (1893). Mi raza. Periódico Patria. Nueva York, 16 de Abril de 1893. [en línea]. Recuperado 16 Abril 2013 de, http://www.josemarti.info/documentos/ mi_raza.html.

. (S/D). Apuntes para el discurso sobre Echegaray. [en línea]. Recuperado 12 Diciembre 2016 de, http://www.josemarti.cu/wp-content/uploads/2014/06/09_
APUNTES_PARA_EL_DISCURSO_SOBRE_ECHEGARAY.pdf.

Morales, E. (2010). La problemática racial en Cuba. Algunos de sus desafíos. Editorial José Martí.

ONU. (2001). Declaración y Programa de Acción de Durban/ Conferencia Mundial contra el Racismo, la Discriminación Racial, la Xenofobia y las Formas Conexas de Intolerancia. [en línea]. Recuperado 30 Octubre 2016 de, http://www.oas.org/ es/sla/ddi/docs/afrodescendientes_instrumentos_internacionales_declaracion_programa_accion_durban.pdf.

Pérez, A. (2010). Gerardo Alfonso: "Para mí el racismo es un tema eminentemente cultural". [en línea]. Recuperado 20 Agosto 2011 de, http://www.cubadebate. cu/noticias/2010/10/19/gerardo-alfonso-racismo-tema-eminentemente-cultural/\#. WIZLXSynbIU.

Sautié, M. (2017). Color cubano por la unidad. [en línea]. Recuperado 08 Enero 2017 de, http://www.granma.cu/cultura/2017-01-06/color-cubano-por-la-unidad-06-01-2017-23-01-44.

Torres, R. (2001). "En blanco y negro". Revista Somos Jóvenes. Casa Editora Abril. Junio, pp. 17-22.

UNESCO (1996). "¿De dónde viene el racismo?". Revista El Correo de la UNESCO. Marzo, pp. 10-35.

Zurbano, R. (2013). Para los negros en Cuba la Revolución no ha comenzado aún. [en línea]. Recuperado 17 Mayo 2013 de, http://www.rebelion.org/mostrar. php?tipo=58id=robertozrbanotorres 8 cinic io $=0$. 